\title{
Differences in Physical Activity and Built Environment Perceptions between Younger and Older Adults Living in The Same Rural
}

\author{
Charilaos Papadopoulos ${ }^{1}$, Brent J. Twaddle ${ }^{2}$ \\ ${ }^{1}$ Department of Kinesiology, Pacific Lutheran University, USA \\ ${ }^{2}$ Department of Nutrition, Exercise and Health Sciences, Central Washington University, USA
}

\section{Article Info}

Article history:

Received Feb 16, 2016

Revised Mar 21, 2016

Accepted Apr 27, 2016

\section{Keyword:}

Build environment

Community-based research

Neighborhood

Older adults

Physical activity

\begin{abstract}
This study examined associations between perceptions and physical activity of younger and older adults residing in the same rural/small town community. Thirty-two adults completed interviews about their community and their physical activity. Both groups perceived their neighborhood as pleasant and safe to be active. Fewer older adults perceived their neighborhood as having sidewalks. Younger adults reported being more vigorously active and they were more often utilizing private membership clubs for physical activity. Older adults utilized more public recreational facilities. These results suggest that higher perceived quality of the neighborhood built environment can enhance participation in moderate exercise in older adults.
\end{abstract}

Copyright (c) 2016 Institute of Advanced Engineering and Science. All rights reserved.

\section{Corresponding Author:}

Charilaos Papadopoulos,

Department of Kinesiology,

Pacific Lutheran University,

12180 Park Avenue S., Tacoma, WA 98447, USA

Email: papadoha@plu.edu

\section{INTRODUCTION}

The American College of Sports Medicine [1] has stated that regular physical activity is a significant factor in maintaining a healthy lifestyle. Regular physical activity reduces the risk of premature mortality, coronary heart disease, hypertension, colon cancer, and type II diabetes [1], with some evidence that physical activity, even of moderate intensity, has long-term cognitive benefits (e.g., low incidence of dementia) [2]. However, only $49.7 \%$ of U.S. men and $46.7 \%$ of U.S. women report engaging in regular physical activity [3]. Using NHANES data, Troiano and colleagues [4] found that physical activity measured by accelerometer declines dramatically through later childhood and through adulthood, such that only $2.4 \%$ of adults over the age of 60 attain recommended levels of physical activity.

The number and percentage of older individuals in the United States is growing. Life expectancy in the U.S. has reached 78.8 years [5]. The need for community support to maintain, or increase, the physical fitness and consequent physical and mental health of older adults will intensify in the coming decades. Maintaining regular physical activity behavior may be especially complex for older adults, involving an interaction of environmental factors (e.g., availability and accessibility of sidewalks, equipment and space, traffic) individual-level factors (e.g., physical activity history, beliefs about the importance and impact of exercise, concern about health, locus of control, self-efficacy, sense of well-being), and physical capability. The built environment in which people live may promote or hinder physical activity [6]-[11]. Age appears to be an important determinant of overall physical activity levels, but could also influence the environments in which physical activity occurs and perceptions of such environments [12]. For instance, recreational facilities 
are often designed for specific age groups (e.g., playgrounds in parks), perhaps resulting in the same environment being perceived differently by different age groups.

Built environment studies in physical activity have also generally been limited to metropolitan areas [9]-[11],[13]. The study of individuals living in rural areas is critical, because such individuals are less physically active overall, report greater number of physical activity barriers, including care giving duties, lack of time and lack of energy [14],[15]. Census data from 2005 indicate that $12.5 \%$ of Washington State's population resides in rural communities [16]. Rural populations are generally older, so understanding the influence of rural environments on older populations is particularly important. About $10.7 \%$ of urban populations and $15.3 \%$ of rural populations in Washington State are 65 or older [16].

Environmental factors related to urban or suburban older adults' physical activity may not be the same factors related to rural older adults' physical activity. There also may be differences between younger and older populations within rural areas. Such information is important to evaluate if effective strategies are to be implemented to increase physical activity in the rural older adult population. The present study compares the perceived physical activity environmental (e.g. presence of sidewalks, access to parks and walking pathways, safety, traffic, presence of recreational facilities, etc.) between older and younger adults residing in the same rural/small town community and examines the associations between these perceptions and self-reported physical activity.

\section{RESEARCH METHOD}

\subsection{Population}

Fifty-eight subjects between the ages of 20 and 30 years old or between the ages of 60 and 90 years old were interviewed. Subjects had lived in Kittitas County, Washington for at least the previous 6 months. This study was approved by the Human Subjects Review Board at Central Washington University.

\subsection{Recruitment}

Older adults were recruited via flyers posted at supermarkets and adult living centers and from announcements placed in monthly newsletters. Younger adults were recruited through announcements and flyers posted on the Central Washington University campus.

\subsection{Survey Method}

All participants completed a face-to-face interview. Face-to-face interviews were selected as the most appropriate survey method for both groups to ensure cooperation and increase the completeness and accuracy of data gathered [17],[18]. Interviewing was also helpful in that it gave the interviewers the flexibility to observe the subjects, repeat or clarify questions, and possibly press for additional information when responses seemed incomplete or irrelevant. The interviews were conducted by four trained interviewers and lasted 30-40 minutes per subject. Participant characteristics are provided in Table 1.

\subsection{Measures}

\subsubsection{Environmental Characteristics.}

The Environmental Supports for Physical Activity Questionnaire was used to measure perceived physical environment. This instrument, developed by Ainsworth and colleagues [19], is divided in two sets of items. This 27-item instrument has demonstrated good reliability and validity [20]. In addition, Brownson et al. [21] indicated that this instrument is reasonably reliable and there were questions that have high reliability for rural responders. The first 13 items focus on neighborhood variables. A Likert-type scale is used to assess neighborhood characteristics, social issues, barriers, use, and access. Neighborhood is defined as a 0.5 -mile radius or a 10-minute walk from the responder's home. Neighborhood survey items are presented in Table 2. The second set of items (13-items) focus on community-level variables. These items queried responders to report whether they have used, did not use, or did not have the environmental support for physical activity. Community is defined as a 10-mile radius or 20-drive from the responder's home. Community survey items are presented in Table 3.

\subsubsection{Physical Activity Measures}

The International Physical Activity Questionnaire (IPAQ) was used to measure physical activity. The IPAQ has been used extensively in research and has shown to be both valid and reliable for younger and older adults [22],[23]. Subjects were asked to recall during a typical week the number of days (and how much time per day) that they do the following for at least 10 minutes: a) walking, b) moderate exercise such as bicycling, vacuuming, gardening, or anything that causes small increases in breathing or heart rate, c) vigorous exercise such as running, aerobics, heavy yard work or anything else that causes a large increase in

Differences in Physical Activity and Built Environment Perceptions between .... (Charilaos Papadopoulos) 
breathing or heart rate. Subjects also indicated how many days in a typical week they do strength exercise designed to increase muscle strength or tone such as lifting weights, pull ups, push-ups, or sit-ups.

\subsubsection{Sociodemographic measures}

Participants reported their age, gender, marital status, employment status, and annual household income, level of education, race/ethnicity, height, and weight.

\subsection{Statistics}

Pearson's Chi-Square and Fisher's exact test were used to determine differences between older and younger adults in their environmental perceptions. Follow-up pairwise comparisons were conducted to evaluate the differences between age groups. Based on high skewness, physical activity measures were log transformed. Independent $t$ test of the log transformation was used to determine any differences between older and younger adults. Bivariate correlations were used to examine the relationship between each of the four log transformed measures of physical activity (walking, strength training, moderate and vigorous exercise) and neighborhood environment variables and use of community facilities. Significance level was set to $\mathrm{P}<0.05$.

\section{RESULTS AND ANALYSIS}

\subsection{Results}

The younger adults were more active than the older adults, but only significantly different in the number of days per week engaged in strength training activities and in total time per day participating in vigorous activity (Table 1$)$.

Table 1. Sociodemographic, Anthropometric, and Physical Activity Measures

\begin{tabular}{|c|c|c|}
\hline Measure & $\begin{array}{c}\text { Younger adults } \\
(n=32)\end{array}$ & $\begin{array}{c}\text { Older adults } \\
(n=26)\end{array}$ \\
\hline \multicolumn{3}{|l|}{ Gender (\%) } \\
\hline Male & 40.7 & 38.5 \\
\hline Female & 59.3 & 61.5 \\
\hline \multicolumn{3}{|l|}{ Marital status (\%) } \\
\hline Married & 3.7 & 19.3 \\
\hline Unmarried & 96.3 & 80.7 \\
\hline \multicolumn{3}{|l|}{ Employment (\%) } \\
\hline Employed & 22.2 & 3.8 \\
\hline Unemployed & 77.8 & 96.2 \\
\hline \multicolumn{3}{|l|}{ Education (\%) } \\
\hline High school or less & 0.0 & 38.5 \\
\hline Some college & 85.2 & 38.4 \\
\hline College graduate & 14.8 & 23.1 \\
\hline \multicolumn{3}{|l|}{ Annual income (\%) } \\
\hline$<\$ 5,000$ & 38.5 & 11.5 \\
\hline$\$ 5,000-20,000$ & 42.3 & 34.5 \\
\hline$\$ 20,000-\$ 50,000$ & 11.5 & 30.8 \\
\hline$>\$ 50,000$ & 0 & 7.7 \\
\hline \multicolumn{3}{|l|}{ Ethnicity (\%) } \\
\hline Hispanic/Latino & 3.7 & 0.0 \\
\hline White/Caucasian & 96.3 & 92.3 \\
\hline Native American & 0.0 & 7.7 \\
\hline Age (years) & $23.0 \pm 2.4$ & $78.8 \pm 8.1^{*}$ \\
\hline Height $(\mathrm{cm})$ & $171.5 \pm 17.7$ & $166.0 \pm 10.7$ \\
\hline Weight (kg) & $72.0 \pm 7.1$ & $76.2 \pm 15.8$ \\
\hline Total days per week performing strength activities & $2.9 \pm 1.9$ & $1.3 \pm 2.4^{*}$ \\
\hline Median & 3.0 & 0.0 \\
\hline Total time per day walking (min) & $42.7 \pm 43.1$ & $37.5 \pm 41.8$ \\
\hline Median & 30.0 & 30.0 \\
\hline Total time per day performing moderate activity & $52.4 \pm 49.1$ & $33.1 \pm 41.7$ \\
\hline Median & 30.0 & 15.0 \\
\hline Total time per day performing vigorous activity & $40.8 \pm 35.8$ & $13.7 \pm 27.8^{*}$ \\
\hline Median & 32.5 & 0.0 \\
\hline
\end{tabular}

Both groups generally reported positive perceptions of neighborhood characteristics for physical activity, with the exception of street lighting for walking at night, which was generally reported as less than 
'very good' (Table 2). Older adults were much more likely than younger adults to report a lack of sidewalks in their neighborhood $(\mathrm{p}<.05)$. The probability of older adults reporting a lack of sidewalks in their neighborhood was 4.1 times higher than for younger adults. However, older adults were also more likely to perceive their neighborhood as a pleasant place to walk $(\mathrm{p}<.05$; Table 2$)$. The probability of older adults to perceive their neighborhood as a 'very pleasant' place to walk was about 1.8 times more likely than the younger group. Similarly, older adults perceived that public recreation facilities were in better condition than younger adults ( $\mathrm{P}<0.05$; Table 2$)$. A higher proportion of the younger adults perceived the condition of public recreational facilities as 'fair' or 'poor' compared to the older adults.

Table 2. Perceived Neighborhood Access, Safety, Use, and Characteristics by Age

\begin{tabular}{|c|c|c|c|}
\hline Neighborhood-related survey item & $\begin{array}{l}\text { Younger adults }(\%) \\
(\mathrm{N}=32)\end{array}$ & $\begin{array}{l}\text { Older adults }(\%) \\
(\mathrm{N}=26)\end{array}$ & $\mathrm{P}$ \\
\hline \multicolumn{4}{|l|}{ Access } \\
\hline \multicolumn{3}{|l|}{ Does your neighborhood have any sidewalks? } & $<0.01^{*}$ \\
\hline Yes & 90.6 & 61.5 & \\
\hline No & 9.4 & 38.5 & \\
\hline \multicolumn{3}{|l|}{ Does your neighborhood have any public recreation facilities? } & 0.07 \\
\hline Yes & 71.9 & 48.0 & \\
\hline No & 28.1 & 52.0 & \\
\hline \multicolumn{4}{|l|}{ Characteristics } \\
\hline How would you rate your neighborhood as a place to walk? & & & $0.03^{*}$ \\
\hline Very pleasant & 43.8 & 76.9 & \\
\hline Somewhat pleasant & 53.1 & 19.2 & \\
\hline Not very pleasant & 3.1 & 3.8 & \\
\hline Not at all pleasant & 0 & 0.0 & \\
\hline \multicolumn{3}{|l|}{ For walking in your neighborhood, would you say your sidewalks are: } & 0.12 \\
\hline Very well maintained & 31.0 & 62.5 & \\
\hline Somewhat maintained & 55.2 & 31.3 & \\
\hline Not very well maintained & 13.8 & 6.3 & \\
\hline Not at all maintained & 0 & 0.0 & \\
\hline \multicolumn{3}{|l|}{ In your neighborhood, would you say that unattended dogs are: } & 0.77 \\
\hline A big problem & 3.2 & 0.0 & \\
\hline Somewhat of a problem & 6.5 & 7.7 & \\
\hline Not very much of a problem & 32.3 & 26.9 & \\
\hline Not a problem at all & 58.0 & 65.4 & \\
\hline \multicolumn{3}{|l|}{ How would you rate the condition of your public recreation facilities? } & $0.03^{*}$ \\
\hline Excellent & 12.0 & 45.5 & \\
\hline Good & 44.0 & 54.5 & \\
\hline Fair & 40.0 & 0.0 & \\
\hline Poor & 4.0 & 0.0 & \\
\hline \multicolumn{3}{|c|}{ For walking at night, would you rate the street lighting in your neighborhood as: } & 0.10 \\
\hline Very good & 0.0 & 19.0 & \\
\hline Good & 12.5 & 19.0 & \\
\hline Fair & 37.5 & 28.6 & \\
\hline Poor or very poor & 50.0 & 33.3 & \\
\hline \multicolumn{4}{|l|}{ Barriers } \\
\hline \multicolumn{3}{|l|}{ Would you say the motorized traffic in your neighborhood is: } & 0.66 \\
\hline Heavy & 15.6 & 12.0 & \\
\hline Moderate & 37.5 & 36.0 & \\
\hline Light & 46.9 & 52.0 & \\
\hline \multicolumn{3}{|c|}{ How safe from crime do you consider your neighborhood to be? Would you say } & 0.21 \\
\hline Extremely safe & 25.0 & 46.2 & \\
\hline Quite safe & 65.6 & 42.3 & \\
\hline Slightly safe & 6.2 & 11.5 & \\
\hline Not at all safe & 3.1 & 0.0 & \\
\hline \multicolumn{4}{|l|}{ Social Issues } \\
\hline \multicolumn{3}{|l|}{ Would you say that the people in your neighborhood are: } & 0.08 \\
\hline Very physically active or somewhat physically active & 70.0 & 87.0 & \\
\hline Not very physically active or not at all physically active & 30.0 & 13.0 & \\
\hline \multicolumn{3}{|l|}{ Would you say most people in your neighborhood can be trusted? } & 0.33 \\
\hline Yes & 95.8 & 100.0 & \\
\hline No & 4.2 & 0.0 & \\
\hline \multicolumn{3}{|c|}{$\begin{array}{l}\text { Thinking about how public money is spent in recreation facilities which of the following statements is most } \\
\text { accurate }\end{array}$} & 0.16 \\
\hline Always gets its fair share or often gets fair share & 63.2 & 50.0 & \\
\hline Seldom gets its fair share or never gets its fair share & 36.8 & 50.0 & \\
\hline
\end{tabular}
$* \mathrm{P}<0.05$ 
Older adults were significantly more likely to report using public recreation centers and programs or facilities at places of worship compared to younger adults. In contrast, older adults were less likely than younger adults to report using private or membership only recreational facilities, schools that were open for public recreation activities, and nearby waterways for physical activity (Table 3).

Table 3. Use of Community Resources and Facilities by Age

\begin{tabular}{|c|c|c|c|}
\hline Community-related survey item & $\begin{array}{c}\text { Younger adults } \\
(\%)\end{array}$ & $\begin{array}{c}\text { Older adults } \\
(\%)\end{array}$ & $\mathrm{P}$ \\
\hline \multicolumn{3}{|c|}{ Do you use any private or membership only recreational facilities? } & $<0.01$ \\
\hline Yes & 70.4 & 23.1 & \\
\hline No & 29.6 & 73.1 & \\
\hline \multicolumn{3}{|l|}{ Do you use walking trails? } & 0.98 \\
\hline Use & 34.4 & 34.6 & \\
\hline Do not Use & 56.3 & 53.8 & \\
\hline \multicolumn{3}{|l|}{ Do you use public swimming pools? } & 0.31 \\
\hline Use & 43.8 & 30.8 & \\
\hline \multirow{2}{*}{\multicolumn{3}{|c|}{ Do you use public recreation centers? }} & \\
\hline & & & $<0.01^{*}$ \\
\hline Use & 41.4 & 80.8 & \\
\hline Do not Use & 55.2 & 19.2 & \\
\hline \multicolumn{3}{|l|}{ Do you use bicycle paths or bike trails? } & 0.19 \\
\hline Use & 27.6 & 12.0 & \\
\hline Do not Use & 72.4 & 88.0 & \\
\hline \multicolumn{3}{|l|}{ Do you use parks, playgrounds, or sports fields? } & 0.18 \\
\hline Use & 56.2 & 38.5 & \\
\hline Do not Use & 43.8 & 61.5 & \\
\hline \multicolumn{3}{|c|}{ Do you use schools that are open for public recreation activities? } & $<0.01^{*}$ \\
\hline Use & 55.2 & 8.0 & \\
\hline Do not Use & 44.8 & 92.0 & \\
\hline \multicolumn{3}{|c|}{ Do you use a shopping mall for physical activity/walking program? } & 0.26 \\
\hline Use & 0.0 & 3.8 & \\
\hline Do not Use & 100.0 & 96.2 & \\
\hline \multicolumn{3}{|c|}{ Do you use physical activity programs and facilities at a place of worship? } & $0.02^{*}$ \\
\hline Use & 0.0 & 16.0 & \\
\hline Do not Use & 100.0 & 84.0 & \\
\hline \multicolumn{3}{|c|}{ Do you use nearby waterways for water related physical activity? } & $<0.01^{*}$ \\
\hline Use & 53.1 & 11.5 & \\
\hline Do not Use & 46.9 & 88.5 & \\
\hline
\end{tabular}

For the younger adults, there was a significant $(\mathrm{p}<0.05)$ relationship between walking $(\mathrm{r}=0.36)$ and being vigorously active $(r=0.50)$ and the presence of neighborhood sidewalks (Table 4$)$.

Table 4. Bivariate correlations between neighborhood focus variables and physical activity measures

\begin{tabular}{|c|c|c|c|c|c|c|}
\hline & \multicolumn{2}{|c|}{ Walking } & \multicolumn{2}{|c|}{ Moderate exercise } & \multicolumn{2}{|c|}{ Vigorous exercise } \\
\hline & Older & Younger & Older & Younger & Older & Younger \\
\hline & Adults & Adults & Adults & Adults & Adults & Adults \\
\hline \multicolumn{7}{|l|}{ Access } \\
\hline Neighborhood sidewalk availability & 0.18 & $0.36^{*}$ & $-0.35^{*}$ & -0.23 & 0.23 & $0.50^{*}$ \\
\hline $\begin{array}{l}\text { Neighborhood public recreation facility } \\
\text { availability }\end{array}$ & 0.11 & -0.21 & 0.14 & -0.11 & -0.05 & -0.12 \\
\hline \multicolumn{7}{|l|}{ Characteristics } \\
\hline Pleasantness of neighborhood for walking & 0.07 & -0.09 & -0.06 & -0.21 & -0.22 & 0.06 \\
\hline Sidewalk maintenance & 0.16 & -0.02 & 0.41 & -0.15 & 0.24 & 0.10 \\
\hline Problematic level of unattended dogs & 0.14 & -0.30 & 0.21 & -0.09 & -0.02 & -0.05 \\
\hline Public recreation facility quality & -0.35 & -0.22 & -0.34 & 0.04 & -0.37 & -0.10 \\
\hline Street lighting quality & -0.14 & $0.44^{*}$ & -0.01 & $0.36^{*}$ & -0.01 & $0.38^{*}$ \\
\hline \multicolumn{7}{|l|}{ Barriers } \\
\hline Extent of motorized traffic & -0.16 & 0.02 & 0.03 & 0.19 & 0.08 & 0.14 \\
\hline Safety from crime & -0.18 & -0.12 & $0.40^{*}$ & -0.08 & -0.20 & -0.14 \\
\hline \multicolumn{7}{|l|}{ Social Issues } \\
\hline Activity level of others in neighborhood & 0.16 & -0.27 & -0.13 & $0.35^{*}$ & -0.16 & -0.18 \\
\hline Trustworthiness of neighborhood residents & 0.16 & 0.16 & -0.28 & 0.19 & -0.14 & 0.20 \\
\hline Fairness of recreation resource allocation & 0.27 & -0.03 & 0.18 & 0.07 & 0.21 & -0.32 \\
\hline
\end{tabular}


The quality of street lighting was also positively related to all types of activity among younger adults. For younger adults, moderate physical activity was related to perceiving more active individuals in their neighborhood. For the older adults, there was a significant relationship between safety from crime and moderate exercise $(r=0.40)$. Strength training among older adults was positively related to the quality of public recreation facilities (Table 5 ).

The bivariate analysis revealed a significant relationship between the use of public recreational facilities and moderate $(r=0.36)$, vigorous exercise $(r=0.33)$ (Table 6) and strength training $(r=0.33)$ (Table 5) for younger adults.

Table 5 . Bivariate correlations between use of community facilities and strength training

\begin{tabular}{lcc}
\hline & \multicolumn{2}{c}{ Strength Training } \\
& Older Adults & Younger Adults \\
\hline Public recreation facility quality & $0.65^{*}$ & -0.22 \\
Do you use public recreation centers? & -0.07 & $0.33^{*}$ \\
\hline$* \mathrm{P}<0.05$ & &
\end{tabular}

Table 6. Bivariate correlations between use of community facilities and physical activity measures

\begin{tabular}{|c|c|c|c|c|c|c|}
\hline & \multicolumn{2}{|c|}{ Walking } & \multicolumn{2}{|c|}{ Moderate exercise } & \multicolumn{2}{|c|}{ Vigorous exercise } \\
\hline & $\begin{array}{l}\text { Older } \\
\text { Adults }\end{array}$ & $\begin{array}{l}\text { Younger } \\
\text { Adults }\end{array}$ & $\begin{array}{l}\text { Older } \\
\text { Adults }\end{array}$ & $\begin{array}{l}\text { Younger } \\
\text { Adults }\end{array}$ & $\begin{array}{l}\text { Older } \\
\text { Adults }\end{array}$ & $\begin{array}{c}\text { Younger } \\
\text { Adults }\end{array}$ \\
\hline $\begin{array}{l}\text { Do you use any private or membership } \\
\text { only recreational facilities? }\end{array}$ & -0.32 & -0.01 & $0.35^{*}$ & -0.10 & $0.45^{*}$ & 0.16 \\
\hline Do you use walking trails? & 0.11 & 0.02 & -0.19 & 0.01 & -0.14 & -0.12 \\
\hline Do you use public swimming pools? & -0.01 & 0.03 & -0.14 & -0.04 & $0.44^{*}$ & -0.18 \\
\hline Do you use public recreation centers? & -0.06 & -0.15 & -0.22 & $0.36^{*}$ & -0.07 & $0.33^{*}$ \\
\hline Do you use bicycle paths or bike trails? & -0.15 & -0.11 & 0.02 & -0.11 & -0.20 & -0.19 \\
\hline $\begin{array}{l}\text { Do you use parks, playgrounds, or sports } \\
\text { fields? }\end{array}$ & -0.01 & 0.07 & -0.25 & -0.04 & -0.13 & 0.11 \\
\hline $\begin{array}{l}\text { Do you use schools that are open for } \\
\text { public recreation activities? }\end{array}$ & 0.26 & $0.32^{*}$ & 0.06 & -0.28 & 0.19 & -0.27 \\
\hline $\begin{array}{l}\text { Do you use nearby waterways for water } \\
\text { related physical activity? }\end{array}$ & -0.22 & -0.03 & $0.41^{*}$ & -0.06 & $0.25^{*}$ & -0.13 \\
\hline
\end{tabular}

There was also a positive relation between younger adults use of schools for public recreation and number of days reporting walking $(\mathrm{r}=0.32)$. For older adults, there was a significant relationship between both moderate $(r=0.41)$ and vigorous exercise $(r=0.25)$ and use of nearby waterways and a significant relationship between vigorous exercise and the use of public swimming pools $(r=0.44)$. Among older adults, there was also a significant relationship between both moderate $(r=0.35)$ and vigorous exercise $(r=0.45)$ and the use of private or membership only recreation facilities. Finally, for the older adults there was a significant inverse relationship between sidewalk availability and moderate exercise.

\subsection{Discussion}

Both young and older adults in the same rural/small town community report generally positive perceptions of their community and neighborhood. A higher percentage of older individuals, however, perceived lower sidewalk availability. Older adults were also less likely to report having public recreation facilities available in their neighborhood. Although when such facilities were present, older adults perceived them as in better condition than their younger counterparts and reporting using public recreation facilities, including places of worship, at a higher rate than younger adults. In contrast, younger adults reported using schools, private facilities, and nearby waterways more often for physical activity than older adults.

Physical activity declines with age [1],[4], but in this study there was no significant difference between older and younger adults in the number of days per week spent walking and doing moderate intensity activities. However, younger adults engaged in more strength training and vigorous activities. Several studies have shown the positive effects of strength training on functional activity of older adults [1],[24],[25]. This group of older adults was spending less than two days per week on strength related activities. One possible explanation is the perception that strength training requires the use of a private or membership only clubs. In this study, even though there was a significant relationship between use of private or membership only recreation facilities and vigorous exercise for the older adults, $76 \%$ of them did not use any private or membership only recreational facilities. In contrast, the younger adults were more likely to

Differences in Physical Activity and Built Environment Perceptions between .... (Charilaos Papadopoulos) 
have and use private or membership only recreational facilities, public schools, and nearby waterways compared to older adults.

Despite the age-based difference in strength and vigorous exercise there was no significant relationship between the use of membership only facilities and vigorous and strength related exercise for the younger participants. There were significant associations between the use of public recreational facilities and the number of days participating in strength, moderate, and vigorous activities. Booth et al. [7] in a group of older adults found that a higher proportion of active individuals reported having access to a recreation center, a cycle track, a golf course, a park, and a swimming pool. In this study, a higher proportion of older adult use public recreational facilities compared to younger adults. In addition, for the older adults there was a significant association between the number of days engaging in vigorous activity and public swimming pools.

The majority of older and younger adults perceived their neighborhoods as "quite safe" or "extremely safe." Bivariate analysis indicated a significant relationship between safety from crime and the number of days that older adults participated in moderate intensity activities. This finding is in agreement with Brownson et al. [26]. In their study, the researchers reported that physical activity rates were higher among older adults that perceive their neighborhoods to be safe.

These observations suggest that younger adults were more likely to engage in strength training and vigorous exercise and perform these activities in nearby facilities (e.g. private clubs, schools open to the public, etc). On the contrary, active older adults use public recreational facilities (e.g. senior centers). There was a significant association between the use of public swimming pools and vigorous activity in this population. There was also a significant inverse relationship between presence of sidewalks and moderateintensity exercise. It is possible that the older adults were not engaging in moderate exercise in their neighborhoods due to the lack of sidewalks [27],[28].

Both groups, older and younger, reported that their neighborhoods were "pleasant" or "somewhat pleasant" as a place to walk. The follow-up analysis indicated that the older adults compared to younger adults were more likely to report that their neighborhood was very pleasant. There was also a significant difference between younger and older in their perception of the condition of the public recreational facilities. The majority of the older adults rated those facilities as either excellent (45.5\%) or good (45.5\%), whereas among younger adults, $44 \%$ of them reported that the condition of the recreational facilities were good and another $40 \%$ of them reported that the condition was fair. One possible explanation of the difference is that a higher percentage of older adults use these facilities than younger adults.

A higher percentage of younger adults reported sidewalks in their neighborhoods and the presence of sidewalks was significantly associated with walking and vigorous activity in this population. For the younger group, there was a significant relationship between street lighting and walking and a significant relationship between people that are active in the neighborhood and moderate intensity exercise. These results indicate that the older adults are more likely to engage in physical activity in public recreational facilities that perceive them to be good or excellent, whereas younger adults are more likely to use streets that have sidewalks. These results also suggest that younger adults are affected more by social issues and they tend to exercise at later times of the day. These results are not in agreement with Sallis et al. [6]. In their study, similar to this study's age group of young adults, they found that walking was not associated with any environmental measures. One possible explanation for the difference between the two studies is that the participants in the Sallis et al [6] study were residents of an urban environment whereas the participants in this study were residing in a rural/small town. The majority of the younger adults in this study reported that they perceive their neighborhood as either quite safe or extremely safe and an overwhelming majority of them (95.8\%) reported that people in their neighborhoods can be trusted.

There are several limitations in this study. The sample size is small, however, it represent an appropriate percentage of the entire community. In addition, the researchers used face to face interviews to collect data. Face to face interviews are more time consuming and more expensive to conduct. Another limitation is that the responders were asked about their perception of the built environment and physical activity was self reported. There are a number of studies that has used perceived environment and self reported physical activity as methods to determine the association between the two [12],[29]. In this study, face to face interviews were conducted which may eliminate false reports. In addition, the interviewers were able to repeat and clarify statements that the participants did not understand. Finally, the sampling methodology and the sample size may limit generalizability. Due to the cross-sectional design, causality cannot be determined. 


\section{CONCLUSION}

The aim of this study was to add in the growing body of literature investigating the association between our built environment and physical activity. The study compared a group of older and younger individuals residing in a rural/small town community and found that both groups have positive perceptions of their neighborhood and community. The older individuals, however, were engaging in less days per week in strength and vigorous activity and were less likely to use private clubs, and nearby waterways. On the contrary, younger adults were less likely to use public recreational facilities and perceive the conditions of those facilities as either fair or poor. There was an association between use of waterways and public swimming pools and moderate and vigorous exercise. These results suggest presences of public facilities that offer a variety of programs are important to engage older adult in vigorous exercise and strength training. These results also suggest that city officials need to maintain the neighborhoods in order for the older adults to walk more for recreation and transportation.

\section{ACKNOWLEDGEMENTS}

The authors would like to acknowledge Dr. Melody Madlem and Dr. Brian Saelens for their statistical and editorial assistance. The authors would like to thank all the participants involved in this study.

\section{REFERENCES}

[1] Nelson M. E., et al., "Physical activity and public health in older adults: recommendation from the American College of Sports Medicine and the American Heart Association," MedSciSports Exerc, vol/issue: 39(8), pp. 143545, 2007.

[2] Abbott R. D., et al., "Walking and dementia in physically capable elderly men," JAMA, vol/issue: 292(12), pp. 1447-53, 2004.

[3] "Prevalence of regular physical activity among adults--United States, 2001 and 2005," MMWR Morb Mortal Wkly Rep., vol/issue: 56(46), pp. 1209-12, 2007.

[4] Troiano R. P., et al., "Physical activity in the United States measured by accelerometer," Med Sci Sports Exerc., vol/issue: 40(1), pp. 181-8, 2008.

[5] Products, "Data Briefs," vol. 168, 2014. [cited 2016 Feb 15]. Available from: http://www.cdc.gov/nchs/data/databriefs/db168.htm

[6] Sallis J. F., et al., "Assessing perceived physical environmental variables that may influence physical activity," ResQExercSport, vol/issue: 68(4), pp. 345-51, 1997.

[7] Booth M. L., et al., "Social-cognitive and perceived environment influences associated with physical activity in older Australians," PrevMed, vol/issue: 31(1), pp. 15-22, 2000.

[8] Saelens B. E. \& Handy S. L., "Built environment correlates of walking: a review," Med Sci Sports Exerc., vol/issue: 40(7), pp. S550-66, 2008.

[9] Michael Y., et al., "Measuring the influence of built neighborhood environments on walking in older adults," JAging PhysAct, vol/issue: 14(3), pp. 302-12, 2006.

[10] King W. C., et al., "Objective measures of neighborhood environment and physical activity in older women," AmJPrevMed, vol/issue: 28(5), pp. 461-9, 2005.

[11] Lees E., et al., "Environmental changes to increase physical activity: perceptions of older urban ethnic-minority women," JAging PhysAct, vol/issue: 15(4), pp. 425-38, 2007.

[12] Shigematsu R., et al., "Age differences in the relation of perceived neighborhood environment to walking," Med Sci Sports Exerc, vol/issue: 41(2), pp. 314-21, 2009.

[13] King D., "Neighborhood and individual factors in activity in older adults: results from the neighborhood and senior health study," JAging PhysAct, vol/issue: 16(2), pp. 144-70, 2008.

[14] Wilcox S., et al., "Determinants of leisure time physical activity in rural compared with urban older and ethnically diverse women in the United States," JEpidemiolCommunity Health, vol/issue: 54(9), pp. 667-72, 2000.

[15] Parks S. E., et al., "Differential correlates of physical activity in urban and rural adults of various socioeconomic backgrounds in the United States," JEpidemiolCommunity Health, vol/issue: 57(1), pp. 29-35, 2003.

[16] Washington State Department of Health, "Guidelines for Using Rural/Urban Classifications," 2009. [cited 2009 Jan 28]. Available from: http://www.doh.wa.gov/Data/Guidelines/RuralUrban.htm.

[17] Picavet H. S., "National health surveys by mail or home interview: effects on response," J Epidemiol Community Health, vol/issue: 55(6), pp. 408-13, 2001.

[18] Smeeth L., et al., "Randomised comparison of three methods of administering a screening questionnaire to elderly people: findings from the MRC trial of the assessment and management of older people in the community," BMJ, vol/issue: 323(7326), pp. 1403-7, 2001.

[19] SIP 4-99 Research Group, "Environmental Supports for Physical Activity Questionnaire," Prevention Research Center, Norman J. Arnold School of Public Health, University of South Carolina, 2002.

[20] Kirtland K. A., et al., "Environmental measures of physical activity supports: perception versus reality," AmJPrevMed, vol/issue: 24(4), pp. 323-31, 2003.

[21] Brownson R. C., et al., "Measuring the environment for friendliness toward physical activity: a comparison of the reliability of 3 questionnaires," AmJPublic Health, vol/issue: 94(3), pp. 473-83, 2004.

Differences in Physical Activity and Built Environment Perceptions between .... (Charilaos Papadopoulos) 
[22] Craig C. L., et al., "International physical activity questionnaire: 12-country reliability and validity," MedSciSports Exerc, vol/issue: 35(8), pp. 1381-95, 2003.

[23] Kolbe-Alexander T. L., et al., "Comparison of two methods of measuring physical activity in South African older adults," JAging PhysAct, vol/issue: 14(1), pp. 98-114, 2006.

[24] Brandon L. J., et al., "Resistive training and long-term function in older adults," JAging PhysAct, vol/issue: 12(1), pp. 10-28, 2004.

[25] DiFrancisco-D. J., et al., "Comparison of once-weekly and twice-weekly strength training in older adults," BrJSports Med, vol/issue: 41(1), pp. 19-22, 2007.

[26] Brownson R. C., et al., "Promoting physical activity in rural communities: walking trail access, use, and effects," Am J Prev Med, vol/issue: 18(3), pp. 235-41, 2000.

[27] Hong T. \& Farley T. A., "Urban residents' priorities for neighborhood features. A survey of New Orleans residents after Hurricane Katrina," Am J Prev Med, vol/issue: 34(4), pp. 353-6, 2008.

[28] Reed J. \& Ainsworth B., "Perceptions of environmental supports on the physical activity behaviors of university men and women: a preliminary investigation," J Am Coll Health, vol/issue: 56(2), pp. 199-204, 2007.

[29] Ogilvie D., et al., "Personal and environmental correlates of active travel and physical activity in a deprived urban population," Int J Behav Nutr Phys Act, vol. 5, pp. 43, 2008. 